\title{
Mechanism of protection of adenosine from tert-butoxyl radicals and repair of adenosine radicals by $\alpha$-tocopherol in aqueous solution
}

\author{
G Vijayalakshmi, M Adinarayana* and P Jayaprakash Rao \\ Department of Chemistry, Osmania University, Hyderabad, 500 007, India \\ *Post-Graduate College of Science, Saifabad, Osmania University, Hyderabad, 500 004, India \\ Received 25 March2011, Revised 26 April 2011, Accepted 4 May 2011, Available online 20 May 2011.
}

\begin{abstract}
The rates of oxidation of adenosine and $\alpha$-tocopherol by tert-butoxyl radicals $\left(t\right.$-BuO $\left.0^{*}\right)$ were studied spectrophotometrically. $\mathrm{Radicals}\left(t\right.$-BuO $\left.{ }^{*}\right)$ were generated by the photolysis of tert-butyl hydroperoxide $(t-\mathrm{BuOOH})$ in the presence of tert-butyl alcohol to scavenge ${ }^{\circ} \mathrm{OH}$ radicals. The rates and quantum yields $(\phi)$ of oxidation of $\alpha$-tocopherol by $t$ - $\mathrm{BuO}^{\bullet}$ radicals were determined in the absence and presence of varying concentrations of adenosine. An increase in the concentration of adenosine was found to decrease the rate of oxidation of $\alpha$-tocopherol, suggesting that adenosine and $\alpha$-tocopherol competed for $t-\mathrm{BuO}^{\bullet}$ radicals. From competition kinetics, the rate constant of $\alpha$-tocopherol reaction with $t$ - $\mathrm{BuO}^{*}$ was calculated to be $7.29 \times 10^{8} \mathrm{dm}^{3} \mathrm{~mol}^{-1}$ $\mathrm{s}^{-1}$. The quantum yields $\phi_{\text {expt }}$ and $\phi_{\text {cal }}$ values suggested that $\alpha$-tocopherol not only protected adenosine from $t$-BuO ${ }^{\bullet}$ radicals, but also repaired adenosine radicals, formed by the reaction of adenosine with $t$ - $\mathrm{BuO}^{\bullet}$ radicals.
\end{abstract}

| $\alpha$-tocopherol | adenosine repair $\mid$ - $\mathrm{BuO}^{\bullet}$ radicals $\mid$ oxidation

\section{INTRODUCTION}

The continuous efflux of ROS from endogenous and exogenous sources results in continuous and accumulative oxidative damage to cellular components and alters many cellular functions. Among the biological targets most vulnerable to oxidative damage are proteinaceous enzymes, lipid membranes and DNA [1]. Organic peroxides form an important part of various chemical, pharmaceutical and cosmetic products. Upon reduction or oxidation by the cytochrome P450 enzyme family, by other heme proteins and by low molecular weight metal ion complexes, these hydroperoxides produce alkoxyl and hydroxyl radicals. DNA is one of the main molecular targets of toxic effects of free radicals formed in mammalian cells during respiration, metabolism and phagocytosis. Although lethal effects of the hydroxyl radicals on DNA and its constituents have been extensively studied [2], relatively little is known about the biological effects of alkoxyl radicals and the key cellular targets for these species. Protein [3], lipid [4], amino acid [5] and pyrimidines [6] hydroperoxides in DNA are rapidly decomposed when treated with light, heat and transition metal ions, resulting in formation of alkoxyl radicals. Recent studies have demonstrated that the exposure of

\footnotetext{
Corresponding author at: Department of Chemistry, Osmania University, 500007 India

*Post-Graduate College of Science Saifabad OsmaniaUniversity Hyderabad 500 007, India

E-mail addresses: adinarayana_mundra@live.com
}

cultured cells to alkoxyl radicals results in the generation of DNA strand breaks [7-9], though the mechanism of damage has not been elucidated. Organic oxygen radicals, particularly alkoxyl radicals may participate in metabolic and pathological processes [10]. Previous studies on the reactivity of tertiary butoxyl radicals suggest that these species might be expected to attack both the sugar and the base moieties of DNA [11].

A growing amount of evidence suggests that the dietary intake of phytochemicals plays an important role in maintaining health and protecting against degenerative process including cardiovascular disease and certain cancers $[12,13]$. The protective effects of the antioxidant constituents of fruits and vegetables have been attributed to the carotenoids, vitamins $\mathrm{C}$ and $\mathrm{E}$, flavonoids, etc. Antioxidants are substances, when present in small quantities prevent or delay the oxidation of cellular organelles by minimizing the damaging effects of ROS/RNS or oxidative stress. Under the normal conditions, a balance is maintained between oxidative stress and antioxidant requirements. The endogenous antioxidant defense comes mainly from three different types of systems, viz., antioxidant enzymes e.g. catalase, superoxide dismutase (SOD), metal sequestering proteins e.g. ferritin and low molecular weight molecules such as vitamin-C, vitamin-E etc. However under pathological conditions or during radiation injury, stress and pollution etc., the balance is lost and excessive supplementation of antioxidants is necessary. 
Classically lipid antioxidants have been divided into two groups: primary or chain-breaking antioxidants and secondary or preventive antioxidants. Vitamin-E ( $\alpha$ tocopherol) is an essential nutrient which functions as a chain breaking antioxidant by preventing the propagation of free radical reactions in cell membrane of the human body. It is well recognized for their effective inhibition of lipid oxidation in foods and biological systems $[14,15]$. Since vitamin-E is only synthesized by plants [16], it is a very important dietary nutrient for humans and animals. $\alpha-$ Tocopherol can scavenge chain propagating free radicals like peroxyl radicals and convert the reactive free radicals to inactive products. There is sufficient evidence that a high intake of vitamins particularly $\alpha$-tocopherol may prevent cancer and other diseases [17]. Thus, the studies involving $\alpha$-tocopherol aimed at minimizing the oxidative stress and providing defense against free radical induced stress in diverse clinical and pathological conditions have gained significant importance. From our laboratory, caffeic acid has been reported $[18,19]$ to repair adenosine radicals, in addition to efficiently scavenging of $\mathrm{SO}_{4}{ }^{-}$and tert-butoxyl $\left(t-\mathrm{BuO}^{\circ}\right)$ radicals.

The $t$ - $\mathrm{BuO}^{\bullet}$ radicals have been generated by steady-state photolysis of tert-butyl hydroperoxide in the presence of $t-\mathrm{BuOH}$ to scavenge the hydroxyl radicals in aqueous solution [20]. In the present paper, the reactions of $t$ - $\mathrm{BuO}^{\bullet}$ radicals with adenosine have been studied in the presence of $\alpha$-tocopherol to assess the protection by $\alpha$ tocopherol towards oxidation of adenosine by $t$ - $\mathrm{BuO}^{\bullet}$ radicals and also repaired, if any offered by $\alpha$-tocopherol towards adenosine radicals. Adenosine is used as a model for DNA to understand the protection and repaired by $\alpha$ tocopherol in the present study.

\section{MATERIALS AND METHODS}

Adenosine and $\alpha$-tocopherol were purchased from Sigma Chemical Co., St. Louis, USA and used as received. All solutions were prepared afresh using double-distilled water. tert-Butyl hydroperoxide $(t-\mathrm{BuOOH})$ was used as received from Merck-Schuchardt of Germany. There is no contamination of other peroxides in the assay of the sample. $t-\mathrm{BuOOH}$ was estimated by iodometric method [21].

The irradiations were carried out at room temperature in a quantum yield reactor model QYR-20 supplied by Photophysics, England, attached with $400 \mathrm{~W}$ medium pressure mercury lamp. The quartz cuvette containing the sample was irradiated and the irradiations were interrupted at definite intervals of time and the absorbance was noted. The light intensity corresponding to the irradiating wavelength $(254 \mathrm{~nm})$ was measured using peroxydisulphate chemical actinometry [22]. On photolysis, $t$ - $\mathrm{BuOOH}$ was activated at $254 \mathrm{~nm}$ to generate ${ }^{\circ} \mathrm{OH}$ and $t$ $\mathrm{BuO}^{\bullet}$ radicals by homolytic cleavage of $-\mathrm{O}-\mathrm{O}$-bond [23]. The ${ }^{\circ} \mathrm{OH}$ radicals produced were scavenged using sufficient concentration of $t-\mathrm{BuOH}[20]$. In a typical kinetic run, the aqueous reaction mixture of adenosine, $t-\mathrm{BuOOH}$ and $t$ $\mathrm{BuOH}$ was taken in a specially designed $1 \mathrm{~cm}$ path length quartz cuvette, suitable for both irradiations and absorbance measurements. The absorbance measurements were made at the $\lambda_{\max }$ of adenosine $(260 \mathrm{~nm})$ on a Chemito UV-Visible spectrophotometer (model 2100).

The photochemical reaction of $\alpha$-tocopherol in the presence of $t-\mathrm{BuOOH}$ and other additives, viz., $t-\mathrm{BuOH}$ and adenosine, was followed by measuring the absorbance of $\alpha$ tocopherol at $294 \mathrm{~nm}$ at which adenosine was totally transparent.

It is known that $t-\mathrm{BuOOH}$ is activated to radical reaction by the absorption of light at $254 \mathrm{~nm}$ [22]. However, the substrates used in the present work, viz., $\alpha$-tocopherol and adenosine have strong absorption in this region. But, in the absence of $t-\mathrm{BuOOH}$ in the reaction mixture, $\alpha$ tocopherol, adenosine or $\alpha$-tocopherol-adenosine mixture did not undergo any observable chemical change on shining the light. Even though a small fraction of the total light intensity was absorbed by $t-\mathrm{BuOOH}$ directly in the presence of adenosine and/or $\alpha$-tocopherol, a considerable chemical change was observed with adenosine as well as $\alpha$ tocopherol. If adenosine and $\alpha$-tocopherol acted as only inner filters, the rates of the reaction of adenosine or $\alpha$ tocopherol with $t$ - $\mathrm{BuO}^{\bullet}$ would have been decreased with increase in concentration of adenosine or $\alpha$-tocopherol. But, the results in Tables 1 and 2 were contrary to this. Another fact against the inner filter concept was that the rate of oxidation of $\alpha$-tocopherol in the presence of adenosine would have been much less than the experimentally observed values (Table 4). Hence, we proposed that the excited states of $\alpha$-tocopherol and adenosine acted as sensitizers to transfer energy to $t-\mathrm{BuOOH}$ to produce radical species. This type of sensitizing effect was proposed in similar systems earlier [18]. Therefore, the light intensity at $254 \mathrm{~nm}$ was used to calculate the quantum yields of oxidation of adenosine as well as $\alpha$-tocopherol under different experimental conditions.

\section{RESULTS AND DISCUSSION}

The oxidation of adenosine by $t$ - $\mathrm{BuO} \mathrm{O}^{\bullet}$ radicals was carried out by irradiating the reaction mixture containing known concentrations of adenosine and $t-\mathrm{BuOOH}$ in the presence of sufficient amount of $t-\mathrm{BuOH}$ to scavenge the - OH radicals completely [20]. The reaction was followed by measuring the absorbance of adenosine at $260 \mathrm{~nm}\left(\lambda_{\max }\right.$ of adenosine) with time. The reported [19] initial rates and quantum yields of oxidation of adenosine by $t$ - $\mathrm{BuO}^{\bullet}$ are presented in Table 1. The initial rates of photooxidation of $\alpha$-tocopherol by $t-\mathrm{BuOOH}$ in the presence of $t-\mathrm{BuOH}$ were calculated from the plots of absorbance of $\alpha$-tocopherol at $294 \mathrm{~nm} v$ s time using microcal origin computer program on a personal computer (Table 2). UV-visible absorption spectra of $\alpha$-tocopherol in the presence of $t-\mathrm{BuOOH}$ and $t$ $\mathrm{BuOH}$ at different irradiation times were recorded (Fig. 1). In order to find the protection offered to adenosine by $\alpha$ tocopherol towards oxidation by $t-\mathrm{BuO}^{\circ}$, the reaction mixture containing known concentrations of adenosine, $t$ $\mathrm{BuOOH}$ and $t-\mathrm{BuOH}$ was irradiated in varying 
concentrations of $\alpha$-tocopherol. The reactions were followed by measuring the absorbance of $\alpha$-tocopherol at $294 \mathrm{~nm}$ (Fig. 2) at which adenosine was transparent and the rate data are presented in Table 3. The photooxidation of $\alpha$ tocopherol by $t$ - $\mathrm{BuO}^{\circ}$ at different concentrations of adenosine was also studied (Fig. 3) and the data are presented in Table 4.

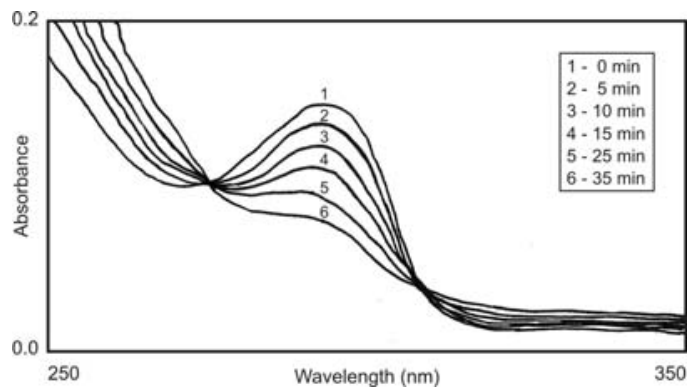

Fig. 1. Absorption spectra of photooxidation of $\alpha$-tocopherol in the presence of $t$-butyl hydroperoxide at different irradiation times; [ $\alpha$ tocopherol $]=5 \times 10^{-5} \mathrm{~mol} \mathrm{dm}{ }^{-3},[t-\mathrm{BuOOH}]=5 \times 10^{-3} \mathrm{~mol} \mathrm{dm}^{-3}$, Light Intensity $=2.7168 \times 10^{15}$ quanta $\mathrm{s}^{-1}, \lambda_{\max }=294 \mathrm{~nm}, \mathrm{pH} \sim$ 7.5 , temperature $=298 \mathrm{~K}$

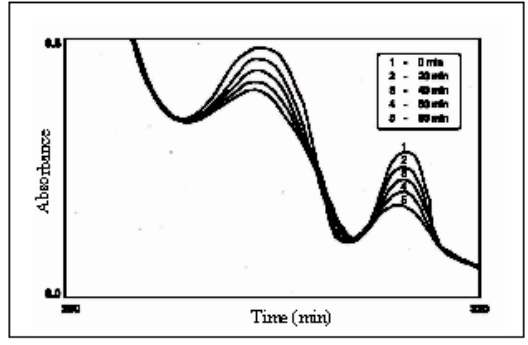

Fig. 2. Absorption spectra of photooxidation of $\alpha$-tocopherol in the presence of $t$-butyl hydroperoxide and adenosine at different irradiation times; $[\alpha$-tocopherol $]=5 \times 10^{-5} \mathrm{~mol} \mathrm{dm}^{-3},[t-\mathrm{BuOOH}]=$ $5 \times 10^{-3} \mathrm{~mol} \mathrm{dm}^{-3}$, [adenosine] $=2 \times 10^{-5} \mathrm{~mol} \mathrm{dm}^{-3}$, Light Intensity $=2.7168 \times 10^{15}$ quanta $\mathrm{s}^{-1}, \lambda_{\max }=324 \mathrm{~nm}, \mathrm{pH} \sim 7.5$, temperature $=298 \mathrm{~K},[t-\mathrm{BuOH}]=1.0 \mathrm{M}$

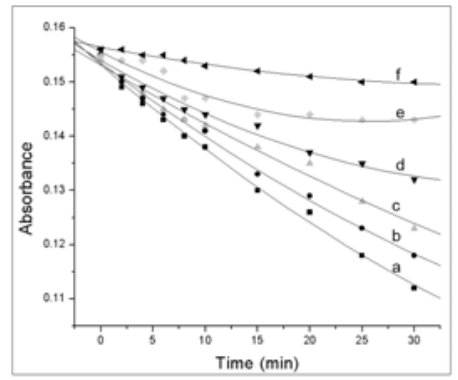

Fig. 3. Effect of varying concentrations of adenosine on the photooxidation of $\alpha$-tocopherol $\left(5 \times 10^{-5} \mathrm{~mol} \mathrm{dm}^{-3}\right)$ in the presence of $t$-BuOOH $\left(5 \times 10^{-3} \mathrm{~mol} \mathrm{dm}^{-3}\right)$ at $298 \mathrm{~K}$. [adenosine] $=$ (a) 0.0 , (b) $5 \times 10^{-5} \mathrm{~mol} \mathrm{dm}^{-3}$, (c) $8 \times 10^{-5} \mathrm{~mol} \mathrm{dm}^{-3}$, (d) $1 \times 10^{-4} \mathrm{~mol} \mathrm{dm}^{-3}$, (e) $3 \times 10^{-4} \mathrm{~mol} \mathrm{dm}^{-3}$,(f) $5 \times 10^{-4} \mathrm{~mol} \mathrm{dm}^{-3}$
The rate of oxidation of adenosine in the presence of $\mathrm{t}-\mathrm{BuOH}$ refers exclusively to the reaction of $t-\mathrm{BuO}^{\circ}$ with adenosine [19]. These rates were found to increase with the increase in concentration of adenosine as well as $t-\mathrm{BuOOH}$. The quantum yield values were also increased with the increase in [adenosine] as well as $[t-\mathrm{BuOOH}]$ (Table 1).

The rate of oxidation of $\alpha$-tocopherol increased with the increase in concentration of $\alpha$-tocopherol (Table 2). The quantum yields of oxidation of $\alpha$-tocopherol were calculated from the initial rates and the light intensity at 254 $\mathrm{nm}$. These values were also increased with the increase in concentration of $\alpha$-tocopherol (Table 2). Having known the rates of $t-\mathrm{BuO}^{\bullet}$ radical reactions with adenosine as well as $\alpha$-tocopherol under varying experimental conditions, both adenosine and $\alpha$-tocopherol were introduced for the competitive studies with $t$ - $\mathrm{BuO}^{\bullet}$ radical. The aqueous solutions of reaction mixture containing $\alpha$-tocopherol, $t$ $\mathrm{BuOOH}$ and $t-\mathrm{BuOH}$ were irradiated in the presence of varying concentrations of adenosine (Fig. 3). The initial rates and quantum yields of oxidation of $\alpha$-tocopherol by $t$ $\mathrm{BuO}^{\bullet}$ radicals were found to decrease with increase in the concentration of adenosine (Table 4). Comparison of the initial rates and quantum yields of oxidation of $\alpha$-tocopherol in the presence and absence of adenosine clearly indicated that the initial rates and quantum yields of oxidation of $\alpha$ tocopherol were substantially decreased in the presence of adenosine (Table 4). These observations clearly demonstrated that adenosine and $\alpha$-tocopherol were in competition for $t-\mathrm{BuO}^{\bullet}$ radicals.

The rate constant of the reaction of $t-\mathrm{BuO}^{\circ}$ with $\alpha$ tocopherol $\left(\mathrm{k}_{\alpha \text {-tocopherol }}=7.29 \times 10^{8} \mathrm{dm}^{3} \mathrm{~mol}^{-1} \mathrm{~s}^{-1}\right)$ has been calculated using the reported [11] rate constant for the reaction of $t-\mathrm{BuO}^{\bullet}$ with adenosine to be $1.40 \times 10^{8} \mathrm{dm}^{3} \mathrm{~mol}^{-1}$ $\mathrm{s}^{-1}$ under similar experimental conditions. The rate constant for the reaction of $t-\mathrm{BuO}^{\bullet}$ with adenosine was calculated by adenosine competition method, which was very similar to the method [24] used to determine the rate constant for the reaction of ${ }^{\circ} \mathrm{OH}$ radicals with polyhydric alcohols in competition with KSCN. In the present study, solutions containing $\alpha$-tocopherol and varying amounts of adenosine in presence of $t-\mathrm{BuOOH}$ and $t-\mathrm{BuOH}$ were irradiated for 2 min and the decrease in absorbance of $\alpha$-tocopherol was measured. The decrease in absorbance of $\alpha$-tocopherol reflected the amount of $t-\mathrm{BuO}^{\bullet}$ radicals that had reacted with $\alpha$-tocopherol. From the known rate constant of the reaction of adenosine with $t-\mathrm{BuO}^{\bullet}$ radical under similar experimental conditions of the present work $\left(\mathrm{k}_{\text {adenosine }}=1.40\right.$ $\left.\times 10^{8} \mathrm{dm}^{3} \mathrm{~mol}^{-1} \mathrm{~s}^{-1}\right)$, the rate constant of $\mathrm{t}-\mathrm{BuO} \mathrm{O}^{\bullet}$ radical reaction with $\alpha$-tocopherol $\left(\mathrm{k}_{\alpha-\text {-tocopherol }}\right)$ can be calculated using equation (1) below.

$$
\frac{[\text { Absorbance of } \alpha \text {-tocopherol }]_{0}}{[\text { Absorbance of } \alpha \text {-tocopherol }]_{\text {adenosine }}}=1+\frac{\mathrm{k}_{\text {adenosine }}[\text { adenosine }]}{\mathrm{k}_{\alpha \text {-tocopherol }}[\alpha \text {-tocopherol }]}
$$


In equation (1), [Absorbance of $\alpha$-tocopherol $]_{0}$ and [Absorbance of $\alpha$-tocopherol $]_{\text {adenosine }}$ are the absorbance values of $\alpha$-tocopherol in the absence and presence of adenosine, respectively at the same interval of time. Using equation (1), the rate constant for the reaction of $t-\mathrm{BuO}^{\circ}$ radical with $\alpha$-tocopherol $\left(\mathrm{k}_{\alpha \text {-tocopherol }}\right)$ was calculated at different concentrations and the average of these was found to be $7.29 \times 10^{8} \mathrm{dm}^{3} \mathrm{~mol}^{-1} \mathrm{~s}^{-1}$.

Table 1. Effect of $[t-\mathrm{BuOOH}]$ and [adenosine] on the rate and quantum yield of photooxidation of adenosine by $t$-BuOOH in the presence of light in aqueous neutral medium

\begin{tabular}{cccc}
\hline $\begin{array}{c}10^{5} \times[\text { adenosine }] \\
\left(\mathrm{mol} \mathrm{dm}^{-3}\right)\end{array}$ & $\begin{array}{c}10^{3} \times[t-\mathrm{BuOOH}] \\
\left(\mathrm{mol} \mathrm{dm}^{-3}\right)\end{array}$ & $\begin{array}{c}10^{10} \times \text { Rate } \\
\left(\mathrm{mol} \mathrm{dm}^{-3} \mathrm{~s}^{-1}\right)\end{array}$ & $\phi_{\text {expt }}$ \\
\hline 1.00 & 5.00 & 2.2183 & 0.000147 \\
2.00 & 5.00 & 2.5866 & 0.000172 \\
4.00 & 5.00 & 3.4362 & 0.000228 \\
& & \\
5.00 & 5.00 & 4.1222 & 0.000274 \\
5.00 & 8.00 & 5.3467 & 0.000356 \\
5.00 & 10.0 & 6.5324 & 0.000434 \\
\hline Light Intensity $=2.7168 \times 10^{15}$ quanta s $^{-1}, \lambda_{\max }=260 \mathrm{~nm}, \mathrm{pH} \sim 7.5$, Temperature $=298 \mathrm{~K},[\mathrm{t}-\mathrm{BuOH}]=1.0 \mathrm{~mol} \mathrm{dm}^{-3}$
\end{tabular}

Table 2. Effect of $[t-\mathrm{BuOOH}]$ and $[\alpha$-tocopherol] on the rate and quantum yield of photooxidation of $\alpha$-tocopherol by $t$-BuOOH in the presence of light in $t-\mathrm{BuOH}-$ water $1: 4(\mathrm{v} / \mathrm{v})$ medium

\begin{tabular}{cccc}
\hline $\begin{array}{c}10^{5} \times[\alpha \text {-tocopherol }] \\
\left(\mathrm{mol} \mathrm{dm}^{-3}\right)\end{array}$ & $\begin{array}{c}10^{3} \times[t-\mathrm{BuOOH}] \\
\left(\mathrm{mol} \mathrm{dm}^{-3}\right)\end{array}$ & $\begin{array}{c}10^{9} \times \text { Rate } \\
\left(\mathrm{mol} \mathrm{dm}^{-3} \mathrm{~s}^{-1}\right)\end{array}$ & $\phi_{\text {expt }}$ \\
\hline 0.5 & 5.0 & 0.6868 & 0.00046 \\
0.8 & 5.0 & 1.6569 & 0.00110 \\
1.0 & 5.0 & 3.6763 & 0.00244 \\
2.0 & 5.0 & 11.627 & 0.00773 \\
5.0 & 5.0 & 33.691 & 0.02241 \\
8.0 & 5.0 & 63.357 & 0.04213 \\
10.0 & 5.0 & 69.840 & 0.04645 \\
5.0 & 1.0 & 19.002 & 0.01263 \\
5.0 & 10.0 & 39.135 & 0.02602 \\
5.0 & 15.0 & 48.754 & 0.03242 \\
\hline
\end{tabular}

Light Intensity $=2.7168 \times 10^{15}$ quanta $^{-1}, \lambda_{\max }=294 \mathrm{~nm}, \mathrm{pH} \sim 7.5$, Temperature $=298 \mathrm{~K}$ 
Table 3. Effect of varying [ $\alpha$-tocopherol] on the rate and quantum yield of photooxidation of $\alpha$-tocopherol by $t$-BuOOH in the absence and presence of adenosine in $t-\mathrm{BuOH}-$ water $1: 4(\mathrm{v} / \mathrm{v})$ neutral medium

\begin{tabular}{cccc}
\hline $\begin{array}{c}10^{5} \times[\alpha \text {-tocopherol }] \\
\left(\mathrm{mol} \mathrm{dm}^{-3}\right)\end{array}$ & $\begin{array}{c}10^{3} \times[\text { adenosine } \\
\left(\mathrm{mol} \mathrm{dm}^{-3}\right)\end{array}$ & $\begin{array}{c}10^{9} \times \text { rate } \\
\left(\mathrm{mol} \mathrm{dm}^{-3} \mathrm{~s}^{-1}\right)\end{array}$ & $\phi_{\text {expt }}$ \\
\hline 0.5 & 0.0 & 0.6868 & 0.00046 \\
0.8 & 0.0 & 1.6569 & 0.00110 \\
1.0 & 0.0 & 3.6763 & 0.00244 \\
2.0 & 0.0 & 11.627 & 0.00773 \\
5.0 & 5.0 & 33.691 & 0.02241 \\
0.5 & 5.0 & 0.2341 & 0.00015 \\
0.8 & 5.0 & 0.9453 & 0.00063 \\
1.0 & 5.0 & 1.8352 & 0.00122 \\
2.0 & 5.0 & 6.5322 & 0.00434 \\
5.0 & & 14.367 & 0.00955 \\
\hline
\end{tabular}

$[t-\mathrm{BuOOH}]=5 \times 10^{-3} \mathrm{~mol} \mathrm{dm}^{-3}$, Light Intensity $=2.7168 \times 10^{15}$ quanta s$^{-1}, \lambda_{\max }=294 \mathrm{~nm}, \mathrm{pH} \sim 7.5$, Room Temperature $=298 \mathrm{~K}$

When the system containing adenosine, $\alpha$ tocopherol and $t-\mathrm{BuOOH}$ in the presence of $t-\mathrm{BuOH}$ was irradiated, the probability of $t-\mathrm{BuO}^{\bullet}$ radicals reacting with $\alpha$-tocopherol $\left\{\mathrm{p}_{(\mathrm{t}-\mathrm{BuO}}+{ }^{-}\right.$-tocopherol $\left.)\right\}$was calculated using equation (2).

$$
\left.\mathrm{p}_{(\mathrm{t}-\mathrm{BuO}}+\alpha \text {-tocopherol }\right)=\frac{\mathrm{k}_{\alpha \text {-tocopherol }}[\alpha \text {-tocopherol }]}{\mathrm{k}_{\text {adenosine }}[\text { adenosine }]+\mathrm{k}_{\alpha \text {-tocopherol }}[\alpha \text {-tocopherol }]}
$$

If $\alpha$-tocopherol scavenged only $t$ - $\mathrm{BuO}^{\bullet}$ radicals and did not give rise to any other reaction (e.g. reaction with adenosine radicals), the quantum yield of oxidation of $\alpha$-tocopherol

$$
\phi_{\text {cal }}=\phi_{\text {expt }}^{\mathrm{o}} \times \mathrm{p}
$$

where $\phi_{\text {expt }}^{o}$ is the quantum yield of oxidation of $\alpha$ tocopherol in the absence of adenosine, and $p$ is the probability given by equation (2).

The calculated quantum yields $\left(\phi_{\text {cal }}\right)$ at different adenosine concentration are presented in Table 4 . The data showed that the $\phi_{\text {cal }}$ values were lower than the experimental values measured quantum yield ( $\phi_{\text {expt }}$ ) values. This indicated that more number of $\alpha$-tocopherol molecules was consumed in the system than expected and the most likely route for this was $\mathrm{H}$ atom donation by $\alpha$-tocopherol to adenosine $\left(\phi_{\text {cal }}\right)$ at each concentration of adenosine may be given by equation (3).

radicals. Table 4 presents the fraction of $t-\mathrm{BuO}^{\bullet}$ radicals scavenged by $\alpha$-tocopherol at different concentrations of adenosine. These values referred to the measure of protection offered to adenosine due to scavenging of $t-\mathrm{BuO}^{\circ}$ radicals by $\alpha$-tocopherol. Using the $\phi_{\text {exptl }}$ values, a set of $\phi^{\prime}$ values was calculated from equation (4), where $\phi^{\prime}$ s indicates the experimentally found quantum yield values if no scavenging of adenosine radicals by $\alpha$-tocopherol occurs. In the absence of any "repair" of adenosine radicals by $\alpha$ 
Vijayalakshmi et al. / Journal of Fundamental Sciences Vol. 7, No. 1 (2011) 24-30.

$$
\phi^{\prime}=\frac{\phi_{\text {expt }}}{p}
$$

tocopherol, the $\phi^{\prime}$ values should all be equal to $\phi_{\text {expt. The }}^{0}$ observed increase in $\phi^{\prime}$ with increasing adenosine concentration (Table 4) clearly indicated the repair of adenosine radicals. The extent of repair may be quantified by equation (5) and the data on percentage repair is presented in Table 4.

$$
\% \text { Repair }=\frac{\left(\phi^{\prime}-\phi_{\text {expt }}^{\mathrm{o}}\right)}{\phi_{\text {expt }}^{\mathrm{o}}} \times 100
$$

The experimentally determined quantum yield $\left(\phi_{\text {expt }}\right)$ values were higher than the quantum yield $\left(\phi_{\text {cal }}\right)$ values calculated using equation (3) under the assumption that $\alpha$-tocopherol acts only as a $t$ - $\mathrm{BuO}^{\bullet}$ radical scavenger. This showed that $\alpha$-tocopherol acted not only as an efficient scavenger of $t-\mathrm{BuO}^{\bullet}$ radicals, but also as an agent for the repair of adenosine radicals. The repair reaction of $\alpha$ tocopherol is explained in terms of the proton donation (Scheme 1).

Adenosine reacts with $t$ - $\mathrm{BuO}^{\bullet}$ radicals to form tertbutoxyl adduct radical, which on hydrolysis gives oxidizing $\mathrm{C}_{8}-\mathrm{OH}$ adduct radical. This oxidizing adduct radical captures an electron from $\alpha$-tocopherol and repaired by dehydroxylation to give the parent molecule adenosine and $\alpha$-tocopherol radical as shown in Scheme 2 .

The $\alpha$-tocopherol radicals were generated in the process of protection of adenosine and repair of adenosine radicals. These radicals were reported $[25,26]$ to have short lifetime, extremely unstable and rapidly convert to unknown compounds at physiological $\mathrm{pH}$ [27]. If $\alpha$ tocopherol radicals reacted with adenosine, then $\phi_{\text {expt }}$ would have been less than $\phi_{\text {cal }}$ values. Contrary to this, the $\phi$ cal values were lower than the experimentally found quantum yield values $\left(\phi_{\text {expt }}\right)$ as shown in Table 4 . This supports our contention that the $\alpha$-tocopherol radicals might not involve in oxidative stress in our experimental conditions.

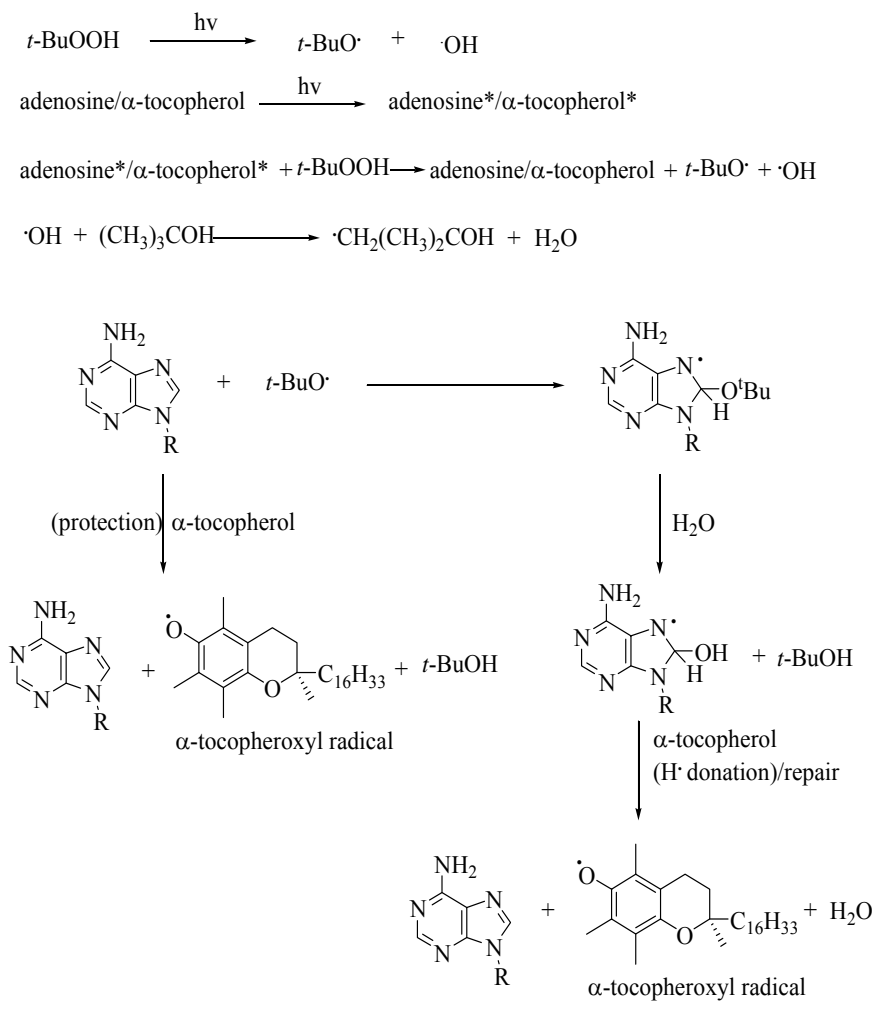

Scheme 1

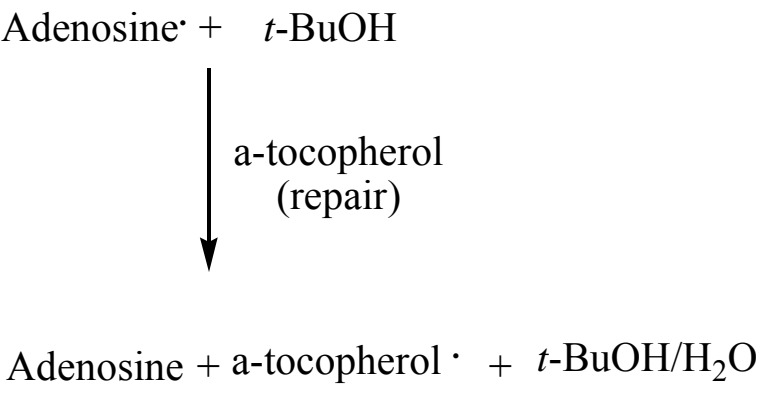

Scheme 2 


\section{CONCLUSIONS}

Our results indicated that adenosine radicals were efficiently repaired by $\alpha$-tocopherol to the extent of $\sim 67 \%$ at about $10 \mu \mathrm{M}$ of $\alpha$-tocopherol concentration. The results also justify that the oxidation of adenosine by $t$-BuO ${ }^{\bullet}$ radicals could be via oxidizing transient radicals of adenosine as suggested earlier [19]. The protection of adenosine and repair of adenosine radicals are summarized in Scheme 2.

\section{ACKNOWLEDGEMENTS}

The authors would like to thank the Head of the Department of Chemistry, Osmania University for providing the facilities to carry out the research work.

\section{REFERENCES}

[1] R. Kohen, A. Nyska, Toxicol. Pathol. 30 (2002) 620-650.

[2] C. Von Sonntag, The Chemical basis of Radiation Biology, Taylor \& Francis, London 1987.

[3] J. A. Simpson, S. Narita, S. Geiseg, S. Gebicki, J. M. Gebicki, R. T. Dean, Biochem. J. 282 (1992) 621-624.

[4] S. Gebicki, J. M. Gebicki, Biochem. J. 289 (1993) 743-749.

[5] K. M. Schaic, M. H. Yang, Free Radic. Biol. Med. 20 (1996) 225-242.

[6] W. F. Ho, B. C. Gilbert, M. J. Davies, J. Chem. Soc. Perkin Trans. 2 (1997) 2525-2532.

[7] J. A. Hartley, N. W. Gibson, A. Kilkenny, S. H. Yuspa, Carcinogenesis 8 (1987) 1821-1825.

[8] J. A. Hartley, N. W. Gibson, L. A. Zwelling, S. H. Yuspa, Cancer Res. 45 (1985) 4864-4870.

[9] J. E.Swanger, P. Dolar, J. L. Zweier, P. Kuppusamy, T. W. Kensler, Chem. Res. Toxicol. 4, (1991) 223-228.

[10] F. Hutchinson, Prog. Nucleic Acid Res. Mol. Biol. 32 (1985) 115-154.

[11] M. Erben-Russ, C. Michel, W. Bors, M. Saran, J. Phys. Chem. 91 (1987) 2362-2365.

[12] A. R. Ness, J. W. Powles, Int. J. Epidemiol. 26 (1997) 1-13.

[13] K. A. Steinmetz, J. D. Potter, J. Am. Diet. Assoc. 96 (1996) 1027-1039.

[14] G. W. Burton, A. Joyce, K. U. Ingold, Arch. Biochem. Biophys. 221 (1983) 281-290.

[15] F. A. Oski, New Engl. J. Med. 303 (1980) 454-455.

[16] O. Aruoma, Prooxidant Properties: An Important Consideration for Food Additives and/or Nutrient Components? In Free Radicals and Food Additives (I. O. Aruoma, B. Halliwell, eds.) Taylor and Francis, London pp. 173.

[17] M. Gaziano, J. E. Manson, J. E. Buring, C. H. Hennekens, Ann. NY Acad. Sci. 669 (1992) 249-259.

[18] M. Sudha Swaraga, M. Adinarayana, Indian J. Biochem. Biophys. 40 (2003) 27-32.

[19] Charitha, M. Adinarayana, Int. J. Chem. Kinetics 37 (2005) 515-521.

D. Asmus, H. Mockel, A. Henglein, J. Phys. Chem. 77 (1973) 1218-1221.

J. A. Howard, K. U. Ingold, Can. J. Chem, 4, (1967) 793-802.

Ravi Kumar, M. Adinarayana, Proc. Indian Acad. Sci. 112 (2000) 551-557.

W. Bors, C. Michel, M. Saran, Biochem. Biophy. Acta, 796, (1984) 312-319.

S. Akhalaq, S. Al-Baghdad, C. Von Sonntag, Carbohydrate Res. 164 (1987) 71-83.

B. Kalyanaraman, Meth. Enzymol, 186 (1990) 333-342.

H. Yamasaki, S.C. Grace, FEBS Lett. 422 (1998) 377-380.

U. Takahama, T. Oniki, Physiol. Plant 101 (1997) 845-852. 